\title{
Photocatalytic rejuvenation enabled self-sanitizing, reusable, and biodegradable masks against COVID-19
}

\author{
Qiang Li, ${ }^{1}$ Yongchao Yin, ${ }^{2}$ Daxian Cao, ${ }^{1}$ Pengcheng Luan, ${ }^{1}$ Ying Wang, ${ }^{1}$ Xiao Sun, ${ }^{1}$ Hongli Zhu ${ }^{1, *}$ \\ ${ }^{1}$ Department of Mechanical and Industrial Engineering, Northeastern University, Boston, MA \\ 02115, USA \\ ${ }^{2}$ Department of Biology, Northeastern University, Boston, MA 02115, USA \\ *Corresponding author: Dr. Hongli Zhu; E-mail: $\underline{\text { h.zhu@ @eu.edu }}$
}

\begin{abstract}
Personal protective equipment (PPE) has been highly recommended by the U.S. Centers for Disease Control and Prevention (CDC) for self-protection under the disastrous SARS-CoV-2 (COVID-19) pandemic. Nevertheless, the massive utilization of PPE, especially the N95 respirators and sing-use masks, encounters significant challenges in recycling and sterilizing the used masks. To tackle the environmental pollution of currently used masks made of synthetic plastic, in this work, we designed a reusable, biodegradable, and antibacterial mask. The mask was prepared by electrospinning of polyvinyl alcohol (PVA), poly(ethylene oxide) (PEO), and cellulose nanofiber (CNF), and with subsequent esterification and then deposition of nitrogendoped $\mathrm{TiO}_{2}\left(\mathrm{~N}-\mathrm{TiO}_{2}\right)$. The fabricated mask containing photocatalytic $\mathrm{N}-\mathrm{TiO}_{2}$ can reach $\sim 100 \%$ sterilization under light source $\left(200-2500 \mathrm{~nm}, 106 \mathrm{Wm}^{-2}\right)$ as 0.1 sun simulation for only 10 min. Thus, the used mask can be rejuvenated through light irradiation and reused, which represents one of the handiest technologies for handling used masks. Furthermore, the intermolecular interactions between PVA, PEO and CNF enhanced electrospinnability and the mechanical performance of the resultant mask. The obtained masks possess superior mechanical strength (10-fold elastic modulus and 2-fold tensile strength higher than a commercial single use mask). The comprised electrospun nanofibers with porous structures in between as well as strong electrostatic attraction enabled breathability ( $83.4 \mathrm{~L} \mathrm{~min}^{-1}$ of air flow rate) and superior particle filterability $(98.7 \%)$. Therefore, this novel mask could be a great alternative to current masks to addressing the urgent need for sustainable, reusable, environmentally friendly, and efficient personal protection designs under the ongoing COVID-19 contagion.
\end{abstract}

Keywords: COVID-19, mask rejuvenation, mask reuse, $\mathrm{N}-\mathrm{TiO}_{2}$, photocatalysis, environmental friendliness

\section{Introduction}

The continuing COVID-19 is highly infectious that the coronavirus could transmit via short-range aerosols and respiratory droplets resulting from sneezing, coughing, and even speaking and breathing. ${ }^{1-3}$ As of today, 11 months after the outbreak of this severe pneumonic disease, 220 countries and regions worldwide have reported the COVID-19 cases, with a total number of 72 million infections, 1.61 million deaths, and over 480 thousand new cases daily. ${ }^{4}$ These numbers are still increasing exponentially. The infected people mainly experience fever, fatigue, dry cough, and such; ${ }^{5,6}$ however, the transmission and pathogenesis of COVID-19 are still uncertain yet. ${ }^{6}$ Therefore, keeping personal protection from the infection remains an urgent and significant challenging issue worldwide. 
Before any effective way can be implemented to preventing the spread of coronavirus, use of personal protective equipment (PPE) such as surgical or medical masks and keeping social distance are still the most efficient self-protection from COVID-19, as recommended by the U.S. Center for Disease Control and Prevention (CDC) as well as many other governments. Current dominant and mostly used masks are N95 respirator and surgical masks, which contain a thin layer of polypropylene (PP) melt blown fabrics to filter out the particles and droplets. Generally, PP fabrics are charged to mount the negative charges on surface, which can help the filtration efficiency of masks. However, the N95 respirators are recommended to be limited to five reuses, and the surgical masks are suggested to be changed every two to four hours, because of the significantly depleted efficiency for filtering bacteria, virus, and other droplets. ${ }^{7}$ Enormous waste masks thereby have been generated during this pandemic, which can induce severe environmental concerns for both waste plastics and the contaminations produced during incineration. ${ }^{8}{ }^{9}$ In Asia, over 2.2 billion pieces of facial masks are consumed daily, which is accompanied with around 17 thousand tons of medical waste every day. ${ }^{10}$ The concerns of environmental dangers produced by single-use masks have been raised in the United Kingdom, where single-use masks would create 66,000 tons of contaminated waste and 57,000 tons of plastic packaging, if everyone consume one mask each day for a year. ${ }^{11}$ More importantly, the used masks from the infected persons could cause the risk of second infection, if they are not properly processed. Therefore, handling of the used masks represents a significant issue for both environmental pollution of plastics and second infection.

To address these challenges, we have developed a rejuvenation strategy with photocatalysis that can sterilize the bacteria facially by light irradiation for only $10 \mathrm{~min}$. The light irradiated mask thereof can be reused or safely discarded, which can save the raw material for mask manufacturing, leverage mask shortage, hinder the second infection from contaminated masks, and facilitate waste mask handling and environmental impacts. Besides the reusability, the mask is designed for synergistically superior biodegradability, mechanical strength, excellent filterability and breathability. First, instead of using the PP plastic as the raw material, we used inherently biodegradable polymers of PVA, PEO, and a wood-derived nanocellulose, which are environmentally friendly. The inherent biodegradability of these polymers can eliminate possible environmental pollution produced by current mask made of petroleum-derived synthetic plastics. Second, we employed electrospinning technology to fabricate composite fabrics with porous structures between the nanofibers, which endow the mask with both excellent breathability and filterability. Third, nanocellulose forms abundant hydrogen bonding with PVA and PEO, while PEO serves as the plasticizer in the electrospinning dopes. Both effects can much improve the electrospinnability and mechanical performance of the prepared mask. All these designs can complement each other to fabricate reusable, biodegradable, high-quality, and environmentally friendly masks that are easy for handling after massive utilization under the COVID-19 pandemic.

\section{Results and Discussion \\ Circular Designing of photon-rejuvenated, reusable, and biodegradable mask}

The massive consumption of the masks under the COVID-19 breakout has rendered the shortage of PP polymers and the disruption of PP supply chains. ${ }^{8}$ The global PP market has been anticipated to grow as much as $7.09 \%$ over last year. ${ }^{12}$ On the other hand, most masks in current market such as N95 respirators, surgical masks and single-use masks encounter significant decline in filtration efficiency after a short utilization, rendered their poor reusability. These masks made of PP thus are generally discarded for post handling, which has raised concerns of both second infection and 
plastic pollution to the environment. As shown in Figure 1, our novel design of the mask enables their antibacterial property and light-rejuvenation $\left(200-2500 \mathrm{~nm}, 106 \mathrm{Wm}^{-2}\right.$ ) by photocatalysis so that the masks can be reused after facial light irradiation. $\mathrm{TiO}_{2}$ has been known as one of the most efficient photocatalytic semiconductors, as long as its advantages of nontoxicity, excellent stability, and cost-effectiveness. Nevertheless, the high bandgap of $\mathrm{TiO}_{2}$ has limited its absorbance only in the UV range. ${ }^{13}$ Doping the nitrogen can reduce the bandgap of $\mathrm{TiO}_{2}$ and thus enhance its photocatalysis under visible light irradiation. ${ }^{14}$ As a result, $\mathrm{N}-\mathrm{TiO}_{2}$ can have an efficient photocatalysis under light irradiation. $\mathrm{N}^{-\mathrm{TiO}_{2}}$ was thus employed to sterilize pathogens and rejuvenate the masks for reuse by simply irradiating the mask under the light for a certain time. In the meantime, we fabricated the mask with circular design by using biodegradable precursor polymers of PVA and PEO as well as a wood-derived nanocellulose instead of synthetic plastics that are environmentally friendly. These polymer blends were designed for intimate intermolecular interactions that can enhance their processibility and the mechanical performance of the resultant mask. We also selected the electrospinning to process polymers for mask manufacturing (Figure 1), which is to produce nanomesh with fine nanofibrous and porous structures to enable the excellence of mask in both breathability and filterability. As a result of the selected biodegradable materials, high surface area from the electrospun nanofibers, photocatalysis, and circular designing, the produced mask can be concurrently functionalized for superior filterability, breathability, mechanical strength, self-sterilization, and environmental friendliness. All these designs could enable an alternative way to fabricate and process next generation reusable and biodegradable masks sustainably.

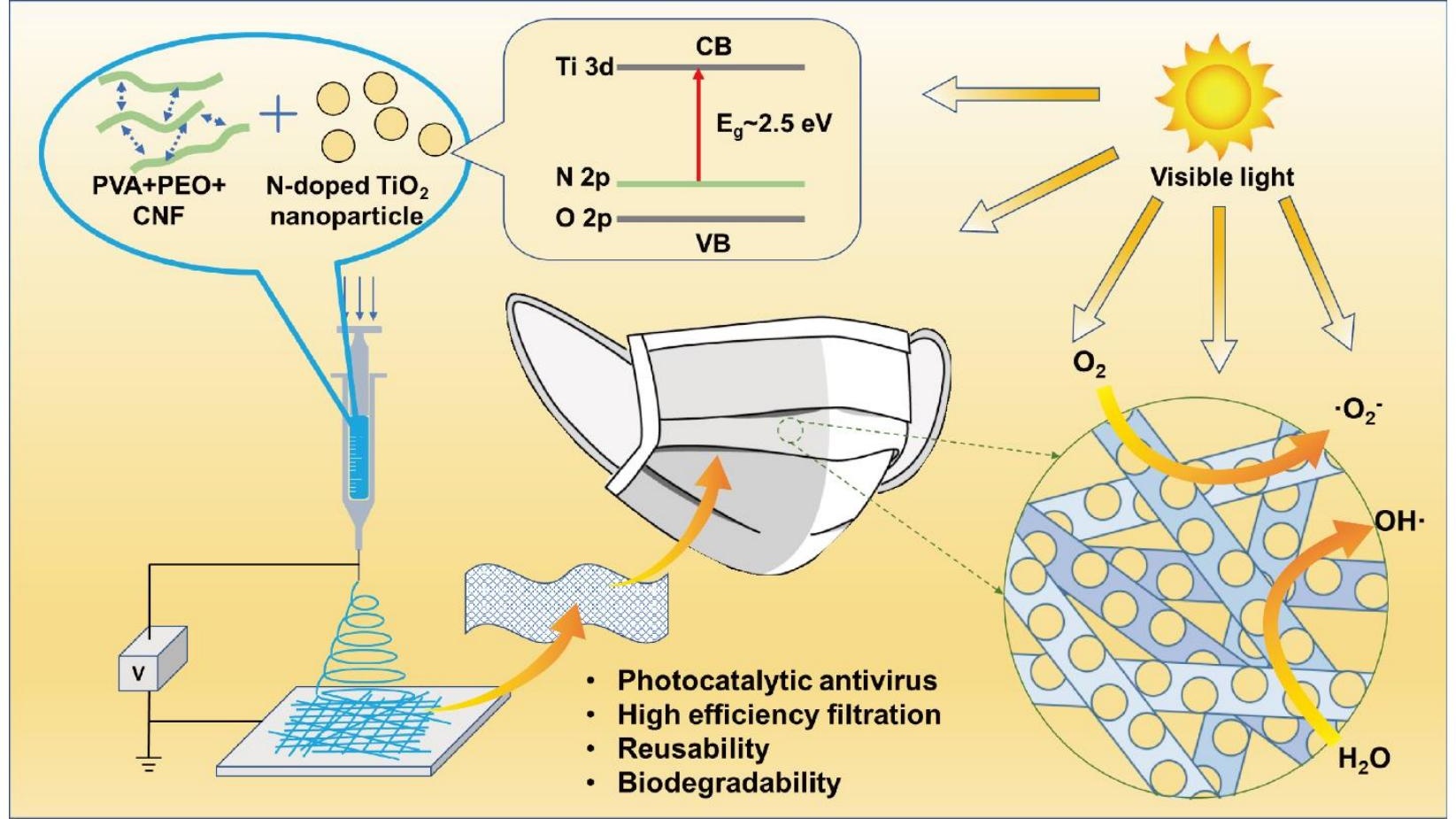

Figure 1. Concept of functional and structural designing of reusable mask. Biodegradable PVA PEO and nanocellulose were electrospun into nanomeshes that were followed by depositing photocatalytic $\mathrm{N}-\mathrm{TiO}_{2}$. PVA, PEO and nanocellulose with inherent biodegradability were used as the starting materials that endow our mask environmental friendliness; the nanocellulose with superior mechanical strength serves as a mechanical reinforcer; the nanofiber-structures developed by the electrospinning can enable the superior breathability and particle filterability; more 
importantly, the $\mathrm{N}-\mathrm{TiO}_{2}$ can efficiently rejuvenate the mask by facial light irradiation to kill the infected bacteria and virus, which make the mask reusable.

\section{Fabrication of masks}

To fabricate the mask with superior antibacterial and rejuvenation properties, commercial P25 $\mathrm{TiO}_{2}$ were doped using urea as the nitrogen source, and then the doped $\mathrm{N}-\mathrm{TiO}_{2}$ was deposited onto the masks to enable their photocatalytic capacity. After the doping, the color of the $\mathrm{TiO}_{2}$ was changed from white to yellow (Figure 2A). The elementary mapping under a scanning transmission electron microscope (S-TEM) confirmed the existence of the doped nitrogen in the $\mathrm{N}-\mathrm{TiO}_{2}$. As shown in the Figure $2 \mathrm{~B}$, the element of nitrogen along with the elements of both titanium and oxygen have been determined. The atomic fraction of the nitrogen elements in the $\mathrm{N}$ $\mathrm{TiO}_{2}$ was semi-quantitatively analyzed by calculating the peak area of the energy dispersive X-ray spectroscopy (EDX). As shown in the Figure S2, the ratio of titanium (26.6\%) and oxygen (61.2\%) was measured close to 1:2, validated the EDX characterization. In the meanwhile, the atom fraction of the nitrogen was measured at $12.2 \%$, demonstrating the successful doping of nitrogen in the $\mathrm{N}$ $\mathrm{TiO}_{2}$. The nitrogen doping has changed the bandgap of the $\mathrm{TiO}_{2}$. As shown in Figure $2 \mathrm{C}, \mathrm{TiO}_{2}$ without nitrogen doping displayed strong absorbance in the UV and near visible light region (320 $\mathrm{nm}-405 \mathrm{~nm}$ ). After the nitrogen doping, the absorbance edge was shifted to $448 \mathrm{~nm}$, and consequently the $\mathrm{N}-\mathrm{TiO}_{2}$ can significantly absorb visible lights. The bandgap energy can be calculated using the Planck's law:

$$
E=\mathrm{h} \times \check{\mathrm{H}}=\mathrm{h} c / 3=1241 / 3
$$

Where $E$ is the bandgap energy $(\mathrm{eV}), \mathrm{h}$ is the Planck constant, $v$ is the frequency of the light, $c$ is the speed of the light $\left(\mathrm{ms}^{-1}\right)$, 3 i was calculated at $3.06 \mathrm{eV}$, which was decreased to $2.77 \mathrm{eV}$ for $\mathrm{N}_{-} \mathrm{TiO}_{2}$. The mimicking light (2002500nm, 50W) we used was with 5.2\% UV light, 37.2\% visible light and $57.6 \%$ infrared light (Table S1); therefore, these results highlighted the photocatalytic activity of the $\mathrm{N}^{-} \mathrm{TiO}_{2}$ under light irradiation by enhancing the visible light excitation.

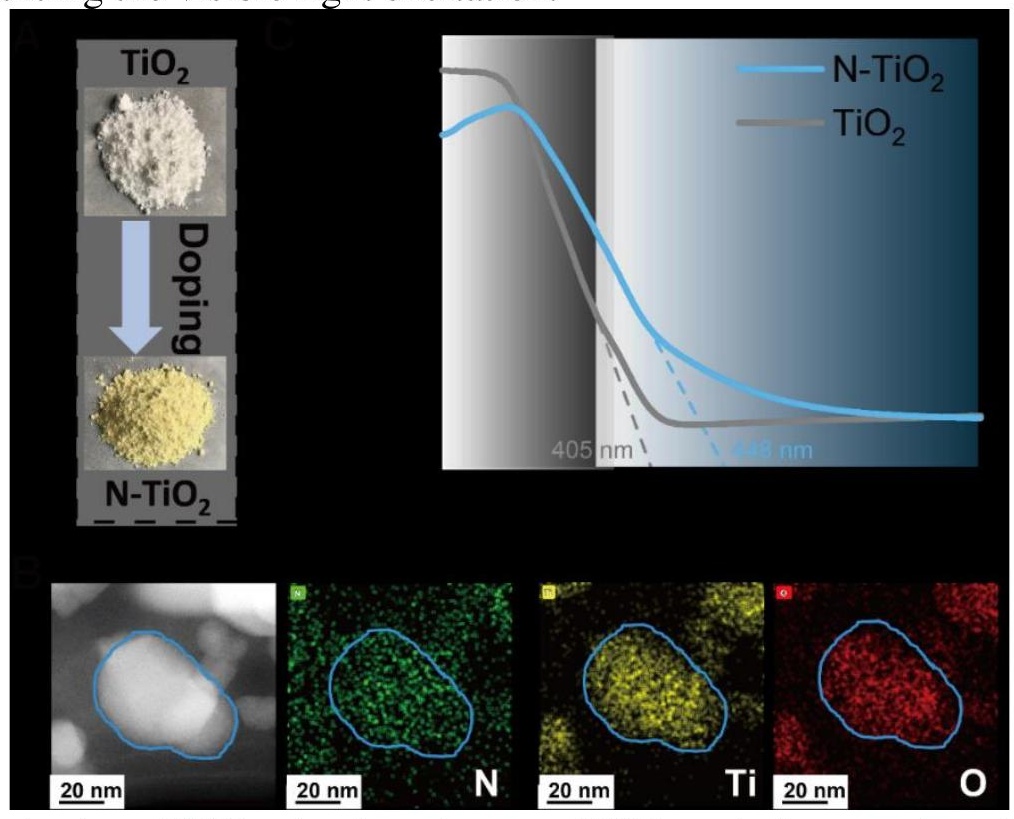

Figure 2. Nitrogen doping of $\mathrm{TiO}_{2}$. A. photo image of $\mathrm{TiO}_{2}$ and nitrogen-doped $\mathrm{TiO}_{2}\left(\mathrm{~N}-\mathrm{TiO}_{2}\right)$. B. STEM image and elemental mapping of $\mathrm{N}-\mathrm{TiO}_{2}$. C. UV-vis spectrum of $\mathrm{TiO}_{2}$ and $\mathrm{N}^{-\mathrm{TiO}_{2}}$. 
importantly, the $\mathrm{N}-\mathrm{TiO}_{2}$ can efficiently rejuvenate the mask by facial light irradiation to kill the infected bacteria and virus, which make the mask reusable.

\section{Fabrication of masks}

To fabricate the mask with superior antibacterial and rejuvenation properties, commercial P25 $\mathrm{TiO}_{2}$ were doped using urea as the nitrogen source, and then the doped $\mathrm{N}-\mathrm{TiO}_{2}$ was deposited onto the masks to enable their photocatalytic capacity. After the doping, the color of the $\mathrm{TiO}_{2}$ was changed from white to yellow (Figure 2A). The elementary mapping under a scanning transmission electron microscope (S-TEM) confirmed the existence of the doped nitrogen in the $\mathrm{N}-\mathrm{TiO}_{2}$. As shown in the Figure $2 \mathrm{~B}$, the element of nitrogen along with the elements of both titanium and oxygen have been determined. The atomic fraction of the nitrogen elements in the $\mathrm{N}$ $\mathrm{TiO}_{2}$ was semi-quantitatively analyzed by calculating the peak area of the energy dispersive X-ray spectroscopy (EDX). As shown in the Figure S2, the ratio of titanium (26.6\%) and oxygen (61.2\%) was measured close to 1:2, validated the EDX characterization. In the meanwhile, the atom fraction of the nitrogen was measured at $12.2 \%$, demonstrating the successful doping of nitrogen in the $\mathrm{N}$ $\mathrm{TiO}_{2}$. The nitrogen doping has changed the bandgap of the $\mathrm{TiO}_{2}$. As shown in Figure $2 \mathrm{C}, \mathrm{TiO}_{2}$ without nitrogen doping displayed strong absorbance in the UV and near visible light region (320 $\mathrm{nm}-405 \mathrm{~nm}$ ). After the nitrogen doping, the absorbance edge was shifted to $448 \mathrm{~nm}$, and consequently the $\mathrm{N}-\mathrm{TiO}_{2}$ can significantly absorb visible lights. The bandgap energy can be calculated using the Planck's law:

$$
E=\mathrm{h} \times \check{\mathrm{H}}=\mathrm{h} c / 3=1241 / 3
$$

Where $E$ is the bandgap energy $(\mathrm{eV}), \mathrm{h}$ is the Planck constant, $v$ is the frequency of the light, $c$ is the speed of the light $\left(\mathrm{ms}^{-1}\right)$, 3 i was calculated at $3.06 \mathrm{eV}$, which was decreased to $2.77 \mathrm{eV}$ for $\mathrm{N}_{-} \mathrm{TiO}_{2}$. The mimicking light (2002500nm, 50W) we used was with 5.2\% UV light, 37.2\% visible light and $57.6 \%$ infrared light (Table S1); therefore, these results highlighted the photocatalytic activity of the $\mathrm{N}^{-} \mathrm{TiO}_{2}$ under light irradiation by enhancing the visible light excitation.

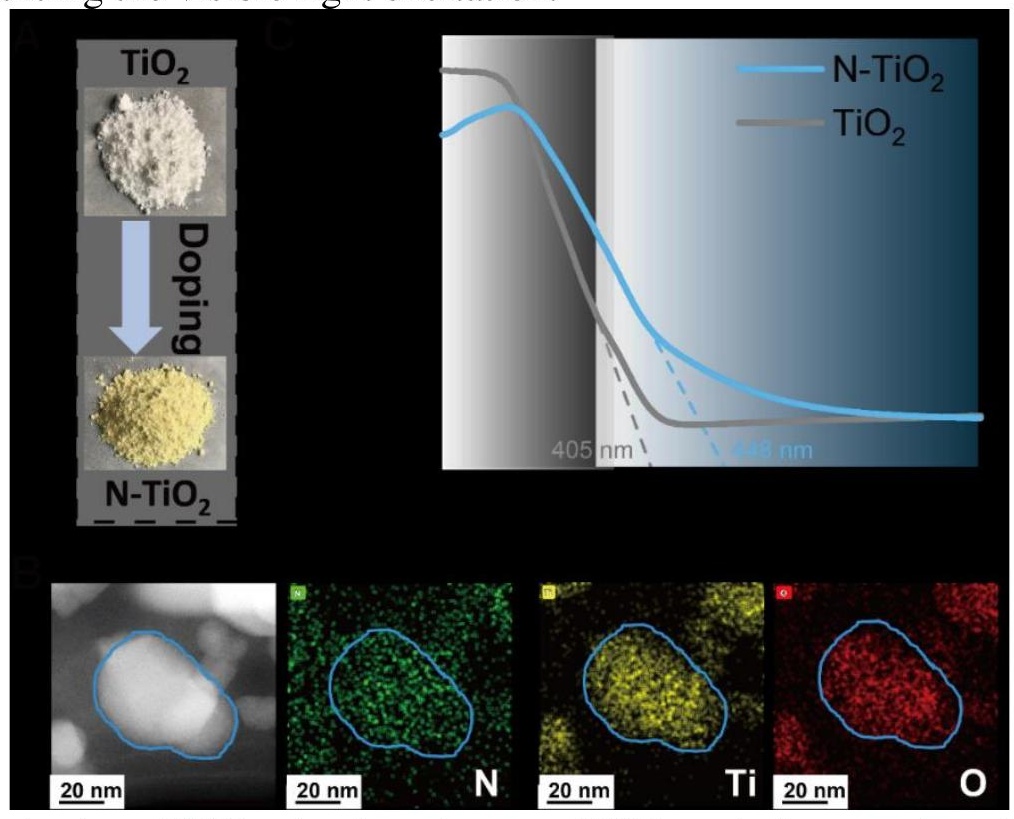

Figure 2. Nitrogen doping of $\mathrm{TiO}_{2}$. A. photo image of $\mathrm{TiO}_{2}$ and nitrogen-doped $\mathrm{TiO}_{2}\left(\mathrm{~N}-\mathrm{TiO}_{2}\right)$. B. STEM image and elemental mapping of $\mathrm{N}-\mathrm{TiO}_{2}$. C. UV-vis spectrum of $\mathrm{TiO}_{2}$ and $\mathrm{N}^{-\mathrm{TiO}_{2}}$. 
importantly, the $\mathrm{N}-\mathrm{TiO}_{2}$ can efficiently rejuvenate the mask by facial light irradiation to kill the infected bacteria and virus, which make the mask reusable.

\section{Fabrication of masks}

To fabricate the mask with superior antibacterial and rejuvenation properties, commercial P25 $\mathrm{TiO}_{2}$ were doped using urea as the nitrogen source, and then the doped $\mathrm{N}-\mathrm{TiO}_{2}$ was deposited onto the masks to enable their photocatalytic capacity. After the doping, the color of the $\mathrm{TiO}_{2}$ was changed from white to yellow (Figure 2A). The elementary mapping under a scanning transmission electron microscope (S-TEM) confirmed the existence of the doped nitrogen in the $\mathrm{N}-\mathrm{TiO}_{2}$. As shown in the Figure $2 \mathrm{~B}$, the element of nitrogen along with the elements of both titanium and oxygen have been determined. The atomic fraction of the nitrogen elements in the $\mathrm{N}$ $\mathrm{TiO}_{2}$ was semi-quantitatively analyzed by calculating the peak area of the energy dispersive X-ray spectroscopy (EDX). As shown in the Figure S2, the ratio of titanium (26.6\%) and oxygen (61.2\%) was measured close to 1:2, validated the EDX characterization. In the meanwhile, the atom fraction of the nitrogen was measured at $12.2 \%$, demonstrating the successful doping of nitrogen in the $\mathrm{N}$ $\mathrm{TiO}_{2}$. The nitrogen doping has changed the bandgap of the $\mathrm{TiO}_{2}$. As shown in Figure $2 \mathrm{C}, \mathrm{TiO}_{2}$ without nitrogen doping displayed strong absorbance in the UV and near visible light region (320 $\mathrm{nm}-405 \mathrm{~nm}$ ). After the nitrogen doping, the absorbance edge was shifted to $448 \mathrm{~nm}$, and consequently the $\mathrm{N}-\mathrm{TiO}_{2}$ can significantly absorb visible lights. The bandgap energy can be calculated using the Planck's law:

$$
E=\mathrm{h} \times \check{\mathrm{H}}=\mathrm{h} c / 3=1241 / 3
$$

Where $E$ is the bandgap energy $(\mathrm{eV}), \mathrm{h}$ is the Planck constant, $v$ is the frequency of the light, $c$ is the speed of the light $\left(\mathrm{ms}^{-1}\right)$, 3 i was calculated at $3.06 \mathrm{eV}$, which was decreased to $2.77 \mathrm{eV}$ for $\mathrm{N}_{-} \mathrm{TiO}_{2}$. The mimicking light (2002500nm, 50W) we used was with 5.2\% UV light, 37.2\% visible light and $57.6 \%$ infrared light (Table S1); therefore, these results highlighted the photocatalytic activity of the $\mathrm{N}^{-} \mathrm{TiO}_{2}$ under light irradiation by enhancing the visible light excitation.

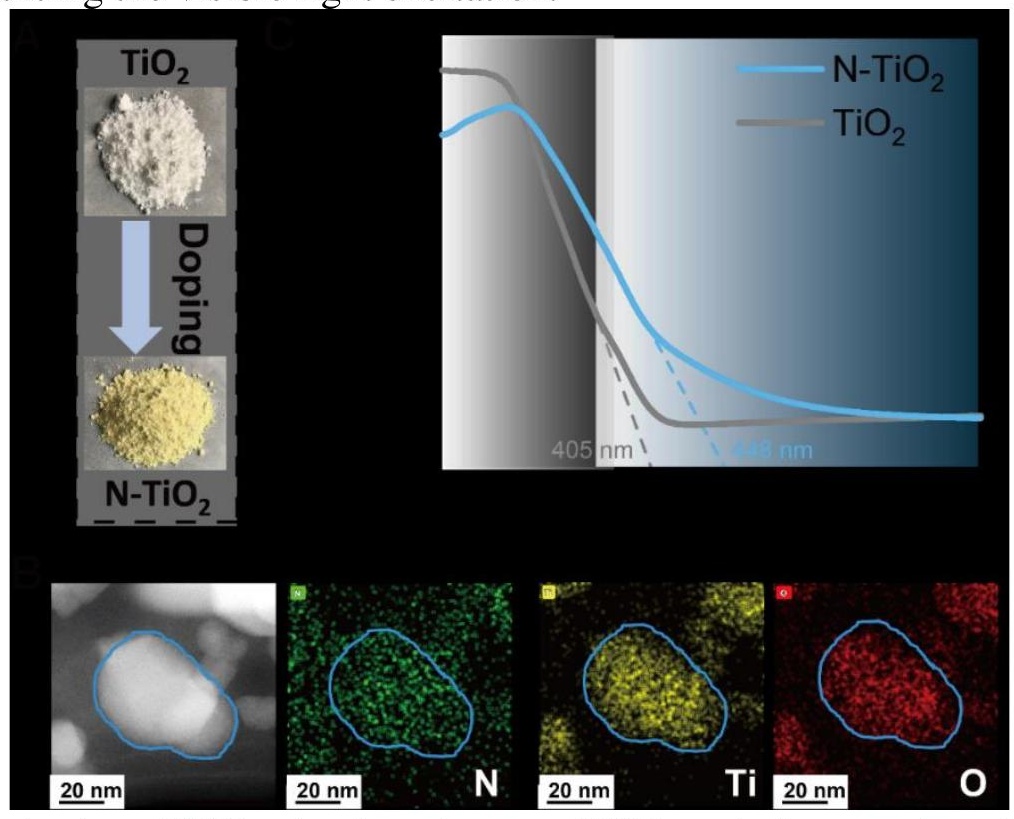

Figure 2. Nitrogen doping of $\mathrm{TiO}_{2}$. A. photo image of $\mathrm{TiO}_{2}$ and nitrogen-doped $\mathrm{TiO}_{2}\left(\mathrm{~N}-\mathrm{TiO}_{2}\right)$. B. STEM image and elemental mapping of $\mathrm{N}-\mathrm{TiO}_{2}$. C. UV-vis spectrum of $\mathrm{TiO}_{2}$ and $\mathrm{N}^{-\mathrm{TiO}_{2}}$. 
importantly, the $\mathrm{N}-\mathrm{TiO}_{2}$ can efficiently rejuvenate the mask by facial light irradiation to kill the infected bacteria and virus, which make the mask reusable.

\section{Fabrication of masks}

To fabricate the mask with superior antibacterial and rejuvenation properties, commercial P25 $\mathrm{TiO}_{2}$ were doped using urea as the nitrogen source, and then the doped $\mathrm{N}-\mathrm{TiO}_{2}$ was deposited onto the masks to enable their photocatalytic capacity. After the doping, the color of the $\mathrm{TiO}_{2}$ was changed from white to yellow (Figure 2A). The elementary mapping under a scanning transmission electron microscope (S-TEM) confirmed the existence of the doped nitrogen in the $\mathrm{N}-\mathrm{TiO}_{2}$. As shown in the Figure $2 \mathrm{~B}$, the element of nitrogen along with the elements of both titanium and oxygen have been determined. The atomic fraction of the nitrogen elements in the $\mathrm{N}$ $\mathrm{TiO}_{2}$ was semi-quantitatively analyzed by calculating the peak area of the energy dispersive X-ray spectroscopy (EDX). As shown in the Figure S2, the ratio of titanium (26.6\%) and oxygen (61.2\%) was measured close to 1:2, validated the EDX characterization. In the meanwhile, the atom fraction of the nitrogen was measured at $12.2 \%$, demonstrating the successful doping of nitrogen in the $\mathrm{N}$ $\mathrm{TiO}_{2}$. The nitrogen doping has changed the bandgap of the $\mathrm{TiO}_{2}$. As shown in Figure $2 \mathrm{C}, \mathrm{TiO}_{2}$ without nitrogen doping displayed strong absorbance in the UV and near visible light region (320 $\mathrm{nm}-405 \mathrm{~nm}$ ). After the nitrogen doping, the absorbance edge was shifted to $448 \mathrm{~nm}$, and consequently the $\mathrm{N}-\mathrm{TiO}_{2}$ can significantly absorb visible lights. The bandgap energy can be calculated using the Planck's law:

$$
E=\mathrm{h} \times \check{\mathrm{H}}=\mathrm{h} c / 3=1241 / 3
$$

Where $E$ is the bandgap energy $(\mathrm{eV}), \mathrm{h}$ is the Planck constant, $v$ is the frequency of the light, $c$ is the speed of the light $\left(\mathrm{ms}^{-1}\right)$, 3 i was calculated at $3.06 \mathrm{eV}$, which was decreased to $2.77 \mathrm{eV}$ for $\mathrm{N}_{-} \mathrm{TiO}_{2}$. The mimicking light (2002500nm, 50W) we used was with 5.2\% UV light, 37.2\% visible light and $57.6 \%$ infrared light (Table S1); therefore, these results highlighted the photocatalytic activity of the $\mathrm{N}^{-} \mathrm{TiO}_{2}$ under light irradiation by enhancing the visible light excitation.

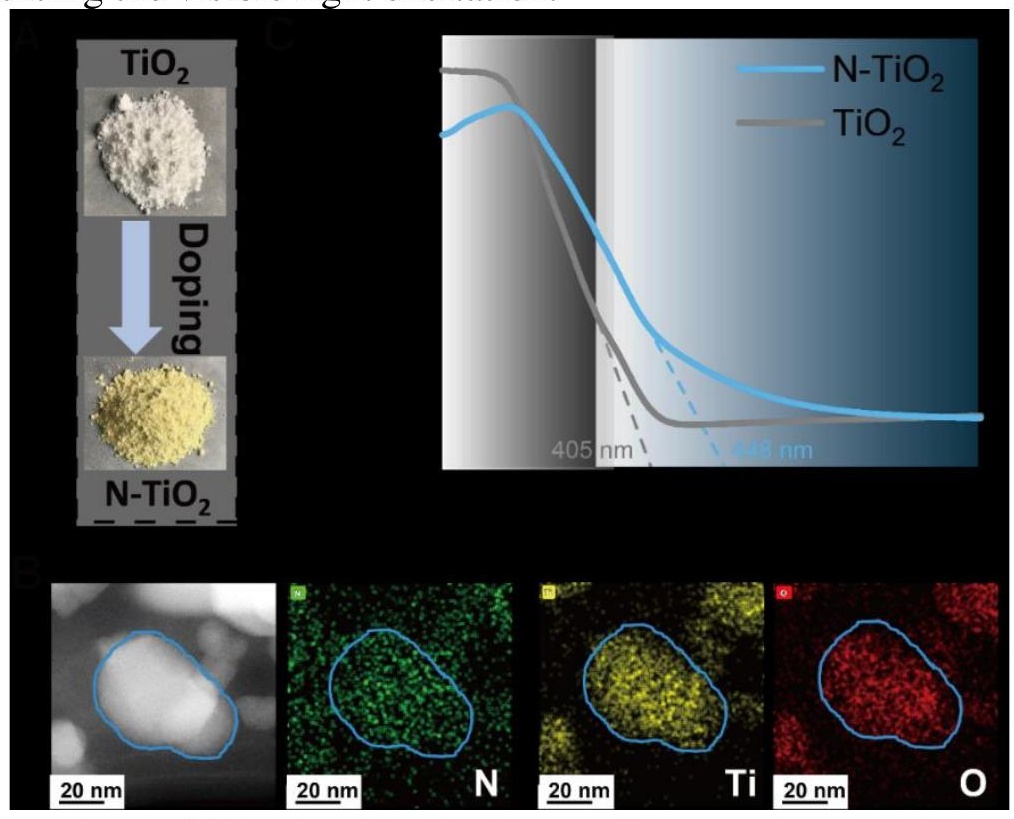

Figure 2. Nitrogen doping of $\mathrm{TiO}_{2}$. A. photo image of $\mathrm{TiO}_{2}$ and nitrogen-doped $\mathrm{TiO}_{2}\left(\mathrm{~N}-\mathrm{TiO}_{2}\right)$. B. STEM image and elemental mapping of $\mathrm{N}-\mathrm{TiO}_{2}$. C. UV-vis spectrum of $\mathrm{TiO}_{2}$ and $\mathrm{N}^{-\mathrm{TiO}_{2}}$. 
importantly, the $\mathrm{N}-\mathrm{TiO}_{2}$ can efficiently rejuvenate the mask by facial light irradiation to kill the infected bacteria and virus, which make the mask reusable.

\section{Fabrication of masks}

To fabricate the mask with superior antibacterial and rejuvenation properties, commercial P25 $\mathrm{TiO}_{2}$ were doped using urea as the nitrogen source, and then the doped $\mathrm{N}-\mathrm{TiO}_{2}$ was deposited onto the masks to enable their photocatalytic capacity. After the doping, the color of the $\mathrm{TiO}_{2}$ was changed from white to yellow (Figure 2A). The elementary mapping under a scanning transmission electron microscope (S-TEM) confirmed the existence of the doped nitrogen in the $\mathrm{N}-\mathrm{TiO}_{2}$. As shown in the Figure $2 \mathrm{~B}$, the element of nitrogen along with the elements of both titanium and oxygen have been determined. The atomic fraction of the nitrogen elements in the $\mathrm{N}$ $\mathrm{TiO}_{2}$ was semi-quantitatively analyzed by calculating the peak area of the energy dispersive X-ray spectroscopy (EDX). As shown in the Figure S2, the ratio of titanium (26.6\%) and oxygen (61.2\%) was measured close to 1:2, validated the EDX characterization. In the meanwhile, the atom fraction of the nitrogen was measured at $12.2 \%$, demonstrating the successful doping of nitrogen in the $\mathrm{N}$ $\mathrm{TiO}_{2}$. The nitrogen doping has changed the bandgap of the $\mathrm{TiO}_{2}$. As shown in Figure $2 \mathrm{C}, \mathrm{TiO}_{2}$ without nitrogen doping displayed strong absorbance in the UV and near visible light region (320 $\mathrm{nm}-405 \mathrm{~nm}$ ). After the nitrogen doping, the absorbance edge was shifted to $448 \mathrm{~nm}$, and consequently the $\mathrm{N}-\mathrm{TiO}_{2}$ can significantly absorb visible lights. The bandgap energy can be calculated using the Planck's law:

$$
E=\mathrm{h} \times \check{\mathrm{H}}=\mathrm{h} c / 3=1241 / 3
$$

Where $E$ is the bandgap energy $(\mathrm{eV}), \mathrm{h}$ is the Planck constant, $v$ is the frequency of the light, $c$ is the speed of the light $\left(\mathrm{ms}^{-1}\right)$, 3 i was calculated at $3.06 \mathrm{eV}$, which was decreased to $2.77 \mathrm{eV}$ for $\mathrm{N}_{-} \mathrm{TiO}_{2}$. The mimicking light (2002500nm, 50W) we used was with 5.2\% UV light, 37.2\% visible light and $57.6 \%$ infrared light (Table S1); therefore, these results highlighted the photocatalytic activity of the $\mathrm{N}^{-} \mathrm{TiO}_{2}$ under light irradiation by enhancing the visible light excitation.

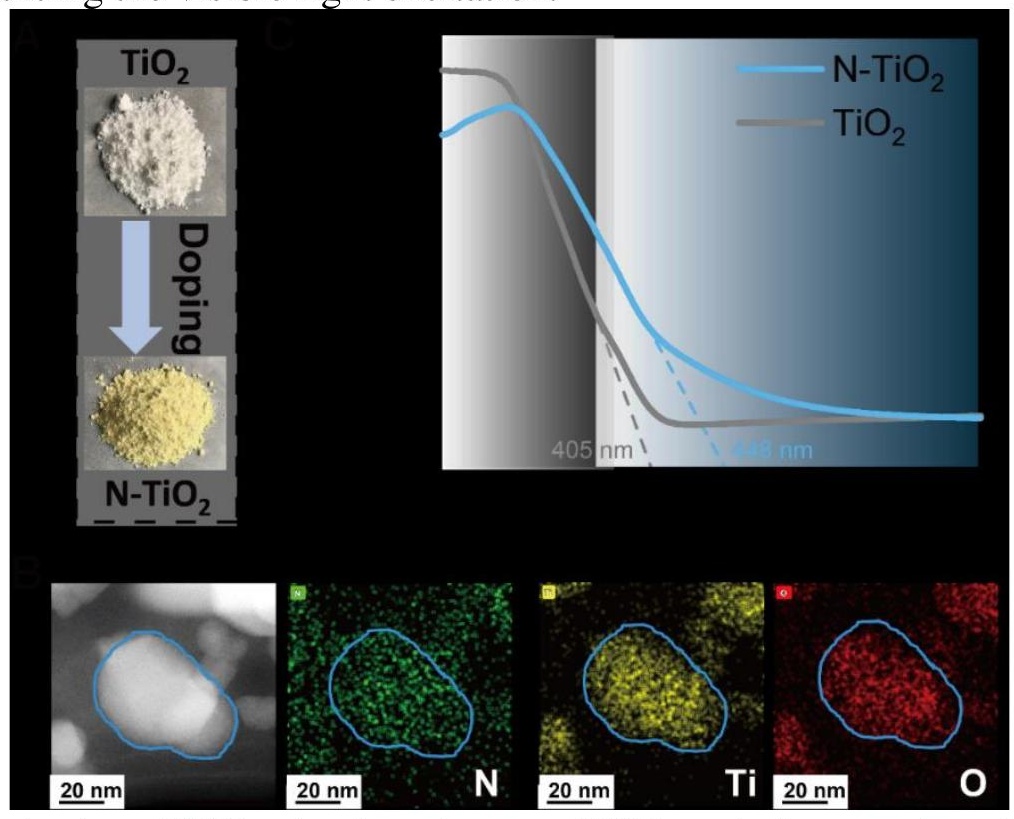

Figure 2. Nitrogen doping of $\mathrm{TiO}_{2}$. A. photo image of $\mathrm{TiO}_{2}$ and nitrogen-doped $\mathrm{TiO}_{2}\left(\mathrm{~N}-\mathrm{TiO}_{2}\right)$. B. STEM image and elemental mapping of $\mathrm{N}-\mathrm{TiO}_{2}$. C. UV-vis spectrum of $\mathrm{TiO}_{2}$ and $\mathrm{N}^{-\mathrm{TiO}_{2}}$. 
importantly, the $\mathrm{N}-\mathrm{TiO}_{2}$ can efficiently rejuvenate the mask by facial light irradiation to kill the infected bacteria and virus, which make the mask reusable.

\section{Fabrication of masks}

To fabricate the mask with superior antibacterial and rejuvenation properties, commercial P25 $\mathrm{TiO}_{2}$ were doped using urea as the nitrogen source, and then the doped $\mathrm{N}-\mathrm{TiO}_{2}$ was deposited onto the masks to enable their photocatalytic capacity. After the doping, the color of the $\mathrm{TiO}_{2}$ was changed from white to yellow (Figure 2A). The elementary mapping under a scanning transmission electron microscope (S-TEM) confirmed the existence of the doped nitrogen in the $\mathrm{N}-\mathrm{TiO}_{2}$. As shown in the Figure $2 \mathrm{~B}$, the element of nitrogen along with the elements of both titanium and oxygen have been determined. The atomic fraction of the nitrogen elements in the $\mathrm{N}$ $\mathrm{TiO}_{2}$ was semi-quantitatively analyzed by calculating the peak area of the energy dispersive X-ray spectroscopy (EDX). As shown in the Figure S2, the ratio of titanium (26.6\%) and oxygen (61.2\%) was measured close to 1:2, validated the EDX characterization. In the meanwhile, the atom fraction of the nitrogen was measured at $12.2 \%$, demonstrating the successful doping of nitrogen in the $\mathrm{N}$ $\mathrm{TiO}_{2}$. The nitrogen doping has changed the bandgap of the $\mathrm{TiO}_{2}$. As shown in Figure $2 \mathrm{C}, \mathrm{TiO}_{2}$ without nitrogen doping displayed strong absorbance in the UV and near visible light region (320 $\mathrm{nm}-405 \mathrm{~nm}$ ). After the nitrogen doping, the absorbance edge was shifted to $448 \mathrm{~nm}$, and consequently the $\mathrm{N}-\mathrm{TiO}_{2}$ can significantly absorb visible lights. The bandgap energy can be calculated using the Planck's law:

$$
E=\mathrm{h} \times \check{\mathrm{H}}=\mathrm{h} c / 3=1241 / 3
$$

Where $E$ is the bandgap energy $(\mathrm{eV}), \mathrm{h}$ is the Planck constant, $v$ is the frequency of the light, $c$ is the speed of the light $\left(\mathrm{ms}^{-1}\right)$, 3 i was calculated at $3.06 \mathrm{eV}$, which was decreased to $2.77 \mathrm{eV}$ for $\mathrm{N}_{-} \mathrm{TiO}_{2}$. The mimicking light (2002500nm, 50W) we used was with 5.2\% UV light, 37.2\% visible light and $57.6 \%$ infrared light (Table S1); therefore, these results highlighted the photocatalytic activity of the $\mathrm{N}^{-} \mathrm{TiO}_{2}$ under light irradiation by enhancing the visible light excitation.

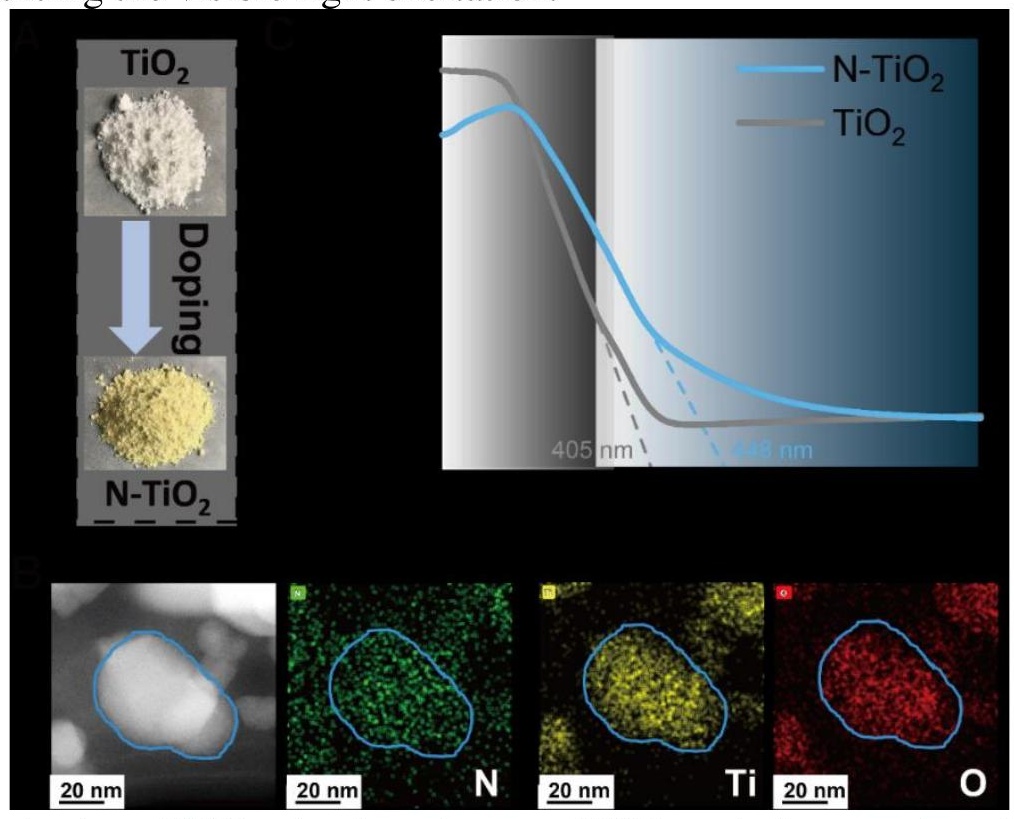

Figure 2. Nitrogen doping of $\mathrm{TiO}_{2}$. A. photo image of $\mathrm{TiO}_{2}$ and nitrogen-doped $\mathrm{TiO}_{2}\left(\mathrm{~N}-\mathrm{TiO}_{2}\right)$. B. STEM image and elemental mapping of $\mathrm{N}-\mathrm{TiO}_{2}$. C. UV-vis spectrum of $\mathrm{TiO}_{2}$ and $\mathrm{N}^{-\mathrm{TiO}_{2}}$. 
importantly, the $\mathrm{N}-\mathrm{TiO}_{2}$ can efficiently rejuvenate the mask by facial light irradiation to kill the infected bacteria and virus, which make the mask reusable.

\section{Fabrication of masks}

To fabricate the mask with superior antibacterial and rejuvenation properties, commercial P25 $\mathrm{TiO}_{2}$ were doped using urea as the nitrogen source, and then the doped $\mathrm{N}-\mathrm{TiO}_{2}$ was deposited onto the masks to enable their photocatalytic capacity. After the doping, the color of the $\mathrm{TiO}_{2}$ was changed from white to yellow (Figure 2A). The elementary mapping under a scanning transmission electron microscope (S-TEM) confirmed the existence of the doped nitrogen in the $\mathrm{N}-\mathrm{TiO}_{2}$. As shown in the Figure $2 \mathrm{~B}$, the element of nitrogen along with the elements of both titanium and oxygen have been determined. The atomic fraction of the nitrogen elements in the $\mathrm{N}$ $\mathrm{TiO}_{2}$ was semi-quantitatively analyzed by calculating the peak area of the energy dispersive X-ray spectroscopy (EDX). As shown in the Figure S2, the ratio of titanium (26.6\%) and oxygen (61.2\%) was measured close to 1:2, validated the EDX characterization. In the meanwhile, the atom fraction of the nitrogen was measured at $12.2 \%$, demonstrating the successful doping of nitrogen in the $\mathrm{N}$ $\mathrm{TiO}_{2}$. The nitrogen doping has changed the bandgap of the $\mathrm{TiO}_{2}$. As shown in Figure $2 \mathrm{C}, \mathrm{TiO}_{2}$ without nitrogen doping displayed strong absorbance in the UV and near visible light region (320 $\mathrm{nm}-405 \mathrm{~nm}$ ). After the nitrogen doping, the absorbance edge was shifted to $448 \mathrm{~nm}$, and consequently the $\mathrm{N}-\mathrm{TiO}_{2}$ can significantly absorb visible lights. The bandgap energy can be calculated using the Planck's law:

$$
E=\mathrm{h} \times \check{\mathrm{H}}=\mathrm{h} c / 3=1241 / 3
$$

Where $E$ is the bandgap energy $(\mathrm{eV}), \mathrm{h}$ is the Planck constant, $v$ is the frequency of the light, $c$ is the speed of the light $\left(\mathrm{ms}^{-1}\right)$, 3 i was calculated at $3.06 \mathrm{eV}$, which was decreased to $2.77 \mathrm{eV}$ for $\mathrm{N}_{-} \mathrm{TiO}_{2}$. The mimicking light (2002500nm, 50W) we used was with 5.2\% UV light, 37.2\% visible light and $57.6 \%$ infrared light (Table S1); therefore, these results highlighted the photocatalytic activity of the $\mathrm{N}^{-} \mathrm{TiO}_{2}$ under light irradiation by enhancing the visible light excitation.

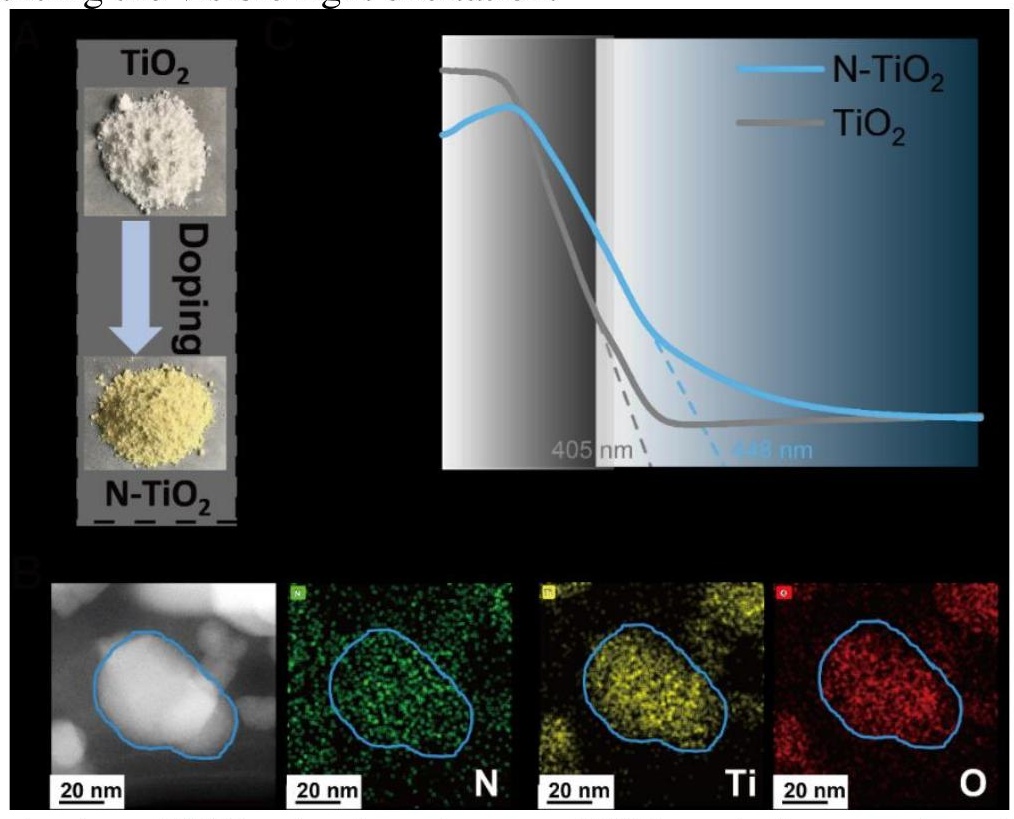

Figure 2. Nitrogen doping of $\mathrm{TiO}_{2}$. A. photo image of $\mathrm{TiO}_{2}$ and nitrogen-doped $\mathrm{TiO}_{2}\left(\mathrm{~N}-\mathrm{TiO}_{2}\right)$. B. STEM image and elemental mapping of $\mathrm{N}-\mathrm{TiO}_{2}$. C. UV-vis spectrum of $\mathrm{TiO}_{2}$ and $\mathrm{N}^{-\mathrm{TiO}_{2}}$. 
importantly, the $\mathrm{N}-\mathrm{TiO}_{2}$ can efficiently rejuvenate the mask by facial light irradiation to kill the infected bacteria and virus, which make the mask reusable.

\section{Fabrication of masks}

To fabricate the mask with superior antibacterial and rejuvenation properties, commercial P25 $\mathrm{TiO}_{2}$ were doped using urea as the nitrogen source, and then the doped $\mathrm{N}-\mathrm{TiO}_{2}$ was deposited onto the masks to enable their photocatalytic capacity. After the doping, the color of the $\mathrm{TiO}_{2}$ was changed from white to yellow (Figure 2A). The elementary mapping under a scanning transmission electron microscope (S-TEM) confirmed the existence of the doped nitrogen in the $\mathrm{N}-\mathrm{TiO}_{2}$. As shown in the Figure $2 \mathrm{~B}$, the element of nitrogen along with the elements of both titanium and oxygen have been determined. The atomic fraction of the nitrogen elements in the $\mathrm{N}$ $\mathrm{TiO}_{2}$ was semi-quantitatively analyzed by calculating the peak area of the energy dispersive X-ray spectroscopy (EDX). As shown in the Figure S2, the ratio of titanium (26.6\%) and oxygen (61.2\%) was measured close to 1:2, validated the EDX characterization. In the meanwhile, the atom fraction of the nitrogen was measured at $12.2 \%$, demonstrating the successful doping of nitrogen in the $\mathrm{N}$ $\mathrm{TiO}_{2}$. The nitrogen doping has changed the bandgap of the $\mathrm{TiO}_{2}$. As shown in Figure $2 \mathrm{C}, \mathrm{TiO}_{2}$ without nitrogen doping displayed strong absorbance in the UV and near visible light region (320 $\mathrm{nm}-405 \mathrm{~nm}$ ). After the nitrogen doping, the absorbance edge was shifted to $448 \mathrm{~nm}$, and consequently the $\mathrm{N}-\mathrm{TiO}_{2}$ can significantly absorb visible lights. The bandgap energy can be calculated using the Planck's law:

$$
E=\mathrm{h} \times \check{\mathrm{H}}=\mathrm{h} c / 3=1241 / 3
$$

Where $E$ is the bandgap energy $(\mathrm{eV}), \mathrm{h}$ is the Planck constant, $v$ is the frequency of the light, $c$ is the speed of the light $\left(\mathrm{ms}^{-1}\right)$, 3 i was calculated at $3.06 \mathrm{eV}$, which was decreased to $2.77 \mathrm{eV}$ for $\mathrm{N}_{-} \mathrm{TiO}_{2}$. The mimicking light (2002500nm, 50W) we used was with 5.2\% UV light, 37.2\% visible light and $57.6 \%$ infrared light (Table S1); therefore, these results highlighted the photocatalytic activity of the $\mathrm{N}^{-} \mathrm{TiO}_{2}$ under light irradiation by enhancing the visible light excitation.

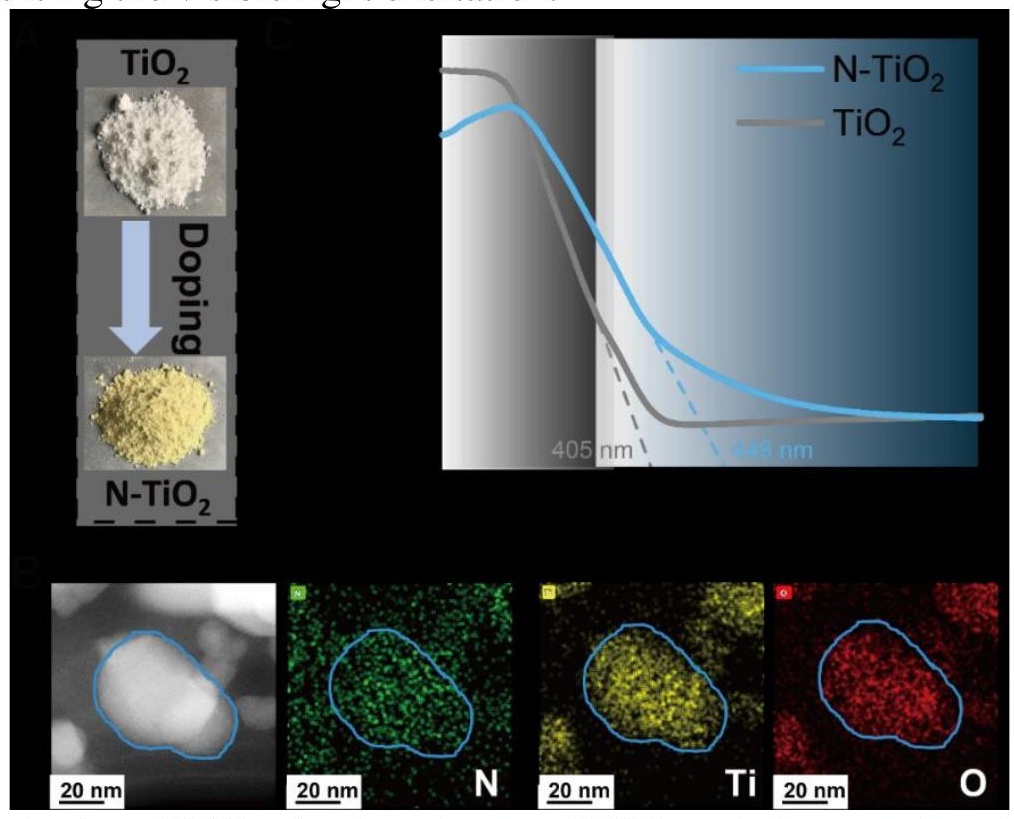

Figure 2. Nitrogen doping of $\mathrm{TiO}_{2}$. A. photo image of $\mathrm{TiO}_{2}$ and nitrogen-doped $\mathrm{TiO}_{2}\left(\mathrm{~N}-\mathrm{TiO}_{2}\right)$. B. STEM image and elemental mapping of $\mathrm{N}-\mathrm{TiO}_{2}$. C. UV-vis spectrum of $\mathrm{TiO}_{2}$ and $\mathrm{N}^{-\mathrm{TiO}_{2}}$. 
importantly, the $\mathrm{N}-\mathrm{TiO}_{2}$ can efficiently rejuvenate the mask by facial light irradiation to kill the infected bacteria and virus, which make the mask reusable.

\section{Fabrication of masks}

To fabricate the mask with superior antibacterial and rejuvenation properties, commercial P25 $\mathrm{TiO}_{2}$ were doped using urea as the nitrogen source, and then the doped $\mathrm{N}-\mathrm{TiO}_{2}$ was deposited onto the masks to enable their photocatalytic capacity. After the doping, the color of the $\mathrm{TiO}_{2}$ was changed from white to yellow (Figure 2A). The elementary mapping under a scanning transmission electron microscope (S-TEM) confirmed the existence of the doped nitrogen in the $\mathrm{N}-\mathrm{TiO}_{2}$. As shown in the Figure $2 \mathrm{~B}$, the element of nitrogen along with the elements of both titanium and oxygen have been determined. The atomic fraction of the nitrogen elements in the $\mathrm{N}$ $\mathrm{TiO}_{2}$ was semi-quantitatively analyzed by calculating the peak area of the energy dispersive X-ray spectroscopy (EDX). As shown in the Figure S2, the ratio of titanium (26.6\%) and oxygen (61.2\%) was measured close to 1:2, validated the EDX characterization. In the meanwhile, the atom fraction of the nitrogen was measured at $12.2 \%$, demonstrating the successful doping of nitrogen in the $\mathrm{N}$ $\mathrm{TiO}_{2}$. The nitrogen doping has changed the bandgap of the $\mathrm{TiO}_{2}$. As shown in Figure $2 \mathrm{C}, \mathrm{TiO}_{2}$ without nitrogen doping displayed strong absorbance in the UV and near visible light region (320 $\mathrm{nm}-405 \mathrm{~nm}$ ). After the nitrogen doping, the absorbance edge was shifted to $448 \mathrm{~nm}$, and consequently the $\mathrm{N}-\mathrm{TiO}_{2}$ can significantly absorb visible lights. The bandgap energy can be calculated using the Planck's law:

$$
E=\mathrm{h} \times \check{\mathrm{H}}=\mathrm{h} c / 3=1241 / 3
$$

Where $E$ is the bandgap energy $(\mathrm{eV}), \mathrm{h}$ is the Planck constant, $v$ is the frequency of the light, $c$ is the speed of the light $\left(\mathrm{ms}^{-1}\right)$, 3 i was calculated at $3.06 \mathrm{eV}$, which was decreased to $2.77 \mathrm{eV}$ for $\mathrm{N}_{-} \mathrm{TiO}_{2}$. The mimicking light (2002500nm, 50W) we used was with 5.2\% UV light, 37.2\% visible light and $57.6 \%$ infrared light (Table S1); therefore, these results highlighted the photocatalytic activity of the $\mathrm{N}^{-} \mathrm{TiO}_{2}$ under light irradiation by enhancing the visible light excitation.

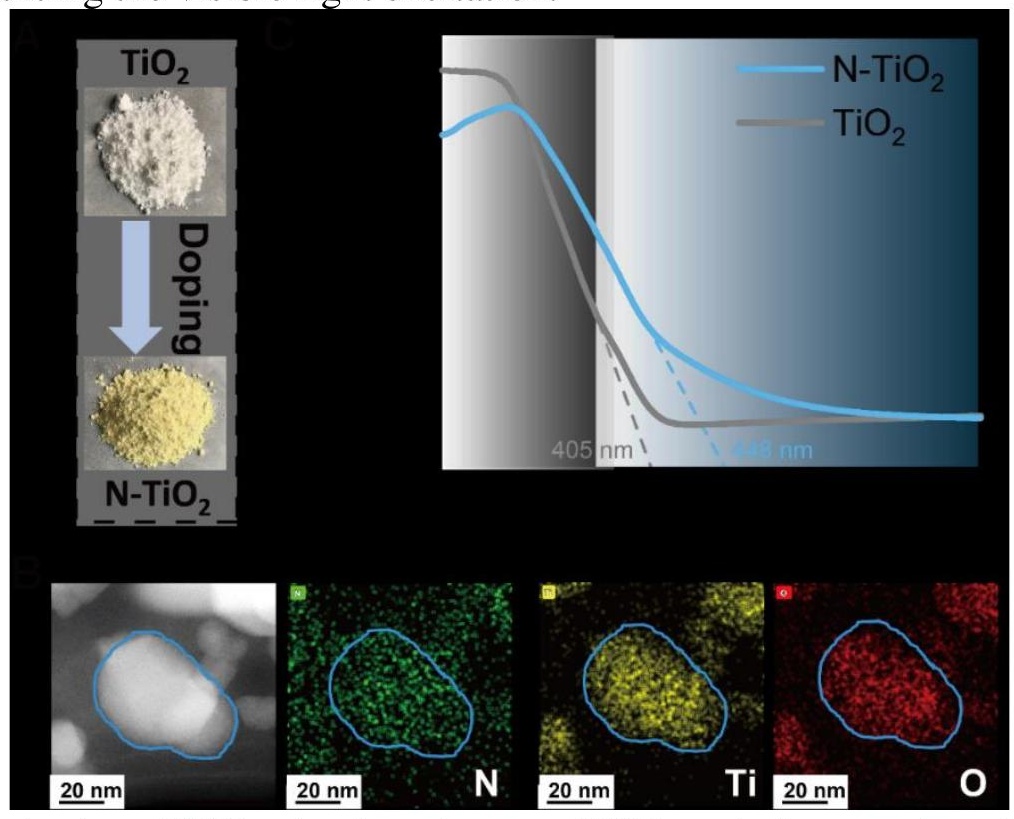

Figure 2. Nitrogen doping of $\mathrm{TiO}_{2}$. A. photo image of $\mathrm{TiO}_{2}$ and nitrogen-doped $\mathrm{TiO}_{2}\left(\mathrm{~N}-\mathrm{TiO}_{2}\right)$. B. STEM image and elemental mapping of $\mathrm{N}-\mathrm{TiO}_{2}$. C. UV-vis spectrum of $\mathrm{TiO}_{2}$ and $\mathrm{N}^{-\mathrm{TiO}_{2}}$. 
importantly, the $\mathrm{N}-\mathrm{TiO}_{2}$ can efficiently rejuvenate the mask by facial light irradiation to kill the infected bacteria and virus, which make the mask reusable.

\section{Fabrication of masks}

To fabricate the mask with superior antibacterial and rejuvenation properties, commercial P25 $\mathrm{TiO}_{2}$ were doped using urea as the nitrogen source, and then the doped $\mathrm{N}-\mathrm{TiO}_{2}$ was deposited onto the masks to enable their photocatalytic capacity. After the doping, the color of the $\mathrm{TiO}_{2}$ was changed from white to yellow (Figure 2A). The elementary mapping under a scanning transmission electron microscope (S-TEM) confirmed the existence of the doped nitrogen in the $\mathrm{N}-\mathrm{TiO}_{2}$. As shown in the Figure $2 \mathrm{~B}$, the element of nitrogen along with the elements of both titanium and oxygen have been determined. The atomic fraction of the nitrogen elements in the $\mathrm{N}$ $\mathrm{TiO}_{2}$ was semi-quantitatively analyzed by calculating the peak area of the energy dispersive X-ray spectroscopy (EDX). As shown in the Figure S2, the ratio of titanium (26.6\%) and oxygen (61.2\%) was measured close to 1:2, validated the EDX characterization. In the meanwhile, the atom fraction of the nitrogen was measured at $12.2 \%$, demonstrating the successful doping of nitrogen in the $\mathrm{N}$ $\mathrm{TiO}_{2}$. The nitrogen doping has changed the bandgap of the $\mathrm{TiO}_{2}$. As shown in Figure $2 \mathrm{C}, \mathrm{TiO}_{2}$ without nitrogen doping displayed strong absorbance in the UV and near visible light region (320 $\mathrm{nm}-405 \mathrm{~nm}$ ). After the nitrogen doping, the absorbance edge was shifted to $448 \mathrm{~nm}$, and consequently the $\mathrm{N}-\mathrm{TiO}_{2}$ can significantly absorb visible lights. The bandgap energy can be calculated using the Planck's law:

$$
E=\mathrm{h} \times \check{\mathrm{H}}=\mathrm{h} c / 3=1241 / 3
$$

Where $E$ is the bandgap energy $(\mathrm{eV}), \mathrm{h}$ is the Planck constant, $v$ is the frequency of the light, $c$ is the speed of the light $\left(\mathrm{ms}^{-1}\right)$, 3 i was calculated at $3.06 \mathrm{eV}$, which was decreased to $2.77 \mathrm{eV}$ for $\mathrm{N}_{-} \mathrm{TiO}_{2}$. The mimicking light (2002500nm, 50W) we used was with 5.2\% UV light, 37.2\% visible light and $57.6 \%$ infrared light (Table S1); therefore, these results highlighted the photocatalytic activity of the $\mathrm{N}^{-} \mathrm{TiO}_{2}$ under light irradiation by enhancing the visible light excitation.

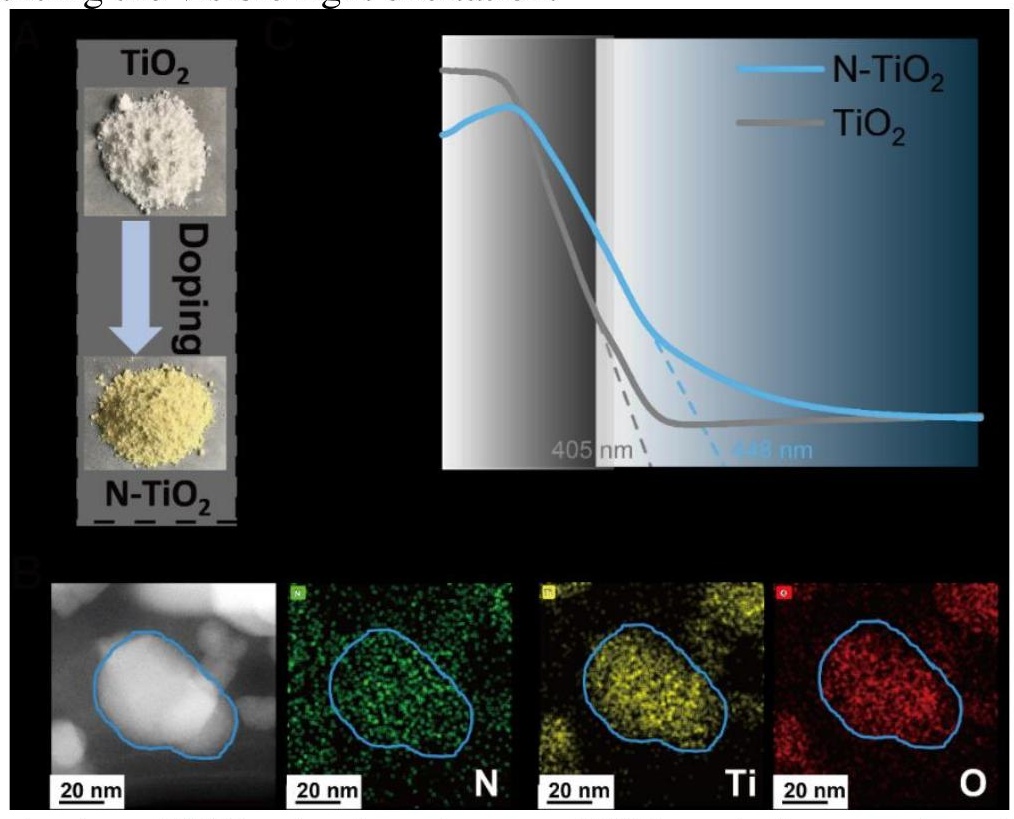

Figure 2. Nitrogen doping of $\mathrm{TiO}_{2}$. A. photo image of $\mathrm{TiO}_{2}$ and nitrogen-doped $\mathrm{TiO}_{2}\left(\mathrm{~N}-\mathrm{TiO}_{2}\right)$. B. STEM image and elemental mapping of $\mathrm{N}-\mathrm{TiO}_{2}$. C. UV-vis spectrum of $\mathrm{TiO}_{2}$ and $\mathrm{N}^{-\mathrm{TiO}_{2}}$. 
importantly, the $\mathrm{N}-\mathrm{TiO}_{2}$ can efficiently rejuvenate the mask by facial light irradiation to kill the infected bacteria and virus, which make the mask reusable.

\section{Fabrication of masks}

To fabricate the mask with superior antibacterial and rejuvenation properties, commercial P25 $\mathrm{TiO}_{2}$ were doped using urea as the nitrogen source, and then the doped $\mathrm{N}-\mathrm{TiO}_{2}$ was deposited onto the masks to enable their photocatalytic capacity. After the doping, the color of the $\mathrm{TiO}_{2}$ was changed from white to yellow (Figure 2A). The elementary mapping under a scanning transmission electron microscope (S-TEM) confirmed the existence of the doped nitrogen in the $\mathrm{N}-\mathrm{TiO}_{2}$. As shown in the Figure $2 \mathrm{~B}$, the element of nitrogen along with the elements of both titanium and oxygen have been determined. The atomic fraction of the nitrogen elements in the $\mathrm{N}$ $\mathrm{TiO}_{2}$ was semi-quantitatively analyzed by calculating the peak area of the energy dispersive X-ray spectroscopy (EDX). As shown in the Figure S2, the ratio of titanium (26.6\%) and oxygen (61.2\%) was measured close to 1:2, validated the EDX characterization. In the meanwhile, the atom fraction of the nitrogen was measured at $12.2 \%$, demonstrating the successful doping of nitrogen in the $\mathrm{N}$ $\mathrm{TiO}_{2}$. The nitrogen doping has changed the bandgap of the $\mathrm{TiO}_{2}$. As shown in Figure $2 \mathrm{C}, \mathrm{TiO}_{2}$ without nitrogen doping displayed strong absorbance in the UV and near visible light region (320 $\mathrm{nm}-405 \mathrm{~nm}$ ). After the nitrogen doping, the absorbance edge was shifted to $448 \mathrm{~nm}$, and consequently the $\mathrm{N}-\mathrm{TiO}_{2}$ can significantly absorb visible lights. The bandgap energy can be calculated using the Planck's law:

$$
E=\mathrm{h} \times \check{\mathrm{H}}=\mathrm{h} c / 3=1241 / 3
$$

Where $E$ is the bandgap energy $(\mathrm{eV}), \mathrm{h}$ is the Planck constant, $v$ is the frequency of the light, $c$ is the speed of the light $\left(\mathrm{ms}^{-1}\right)$, 3 i was calculated at $3.06 \mathrm{eV}$, which was decreased to $2.77 \mathrm{eV}$ for $\mathrm{N}_{-} \mathrm{TiO}_{2}$. The mimicking light (2002500nm, 50W) we used was with 5.2\% UV light, 37.2\% visible light and $57.6 \%$ infrared light (Table S1); therefore, these results highlighted the photocatalytic activity of the $\mathrm{N}^{-} \mathrm{TiO}_{2}$ under light irradiation by enhancing the visible light excitation.

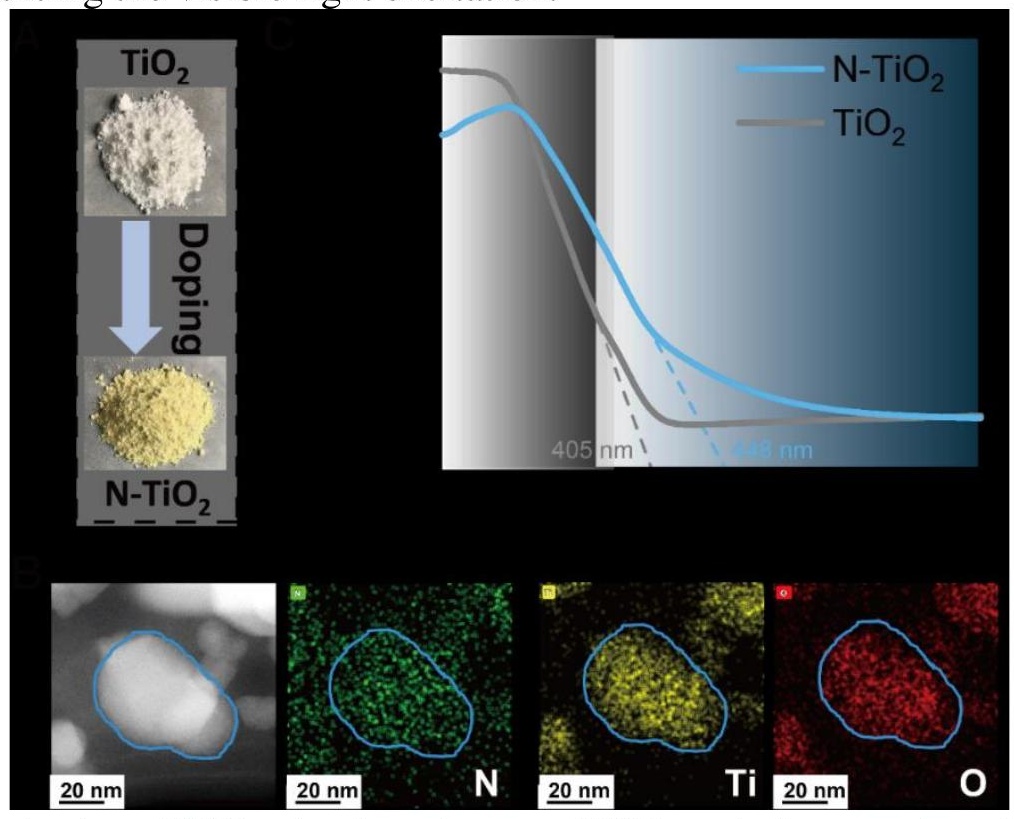

Figure 2. Nitrogen doping of $\mathrm{TiO}_{2}$. A. photo image of $\mathrm{TiO}_{2}$ and nitrogen-doped $\mathrm{TiO}_{2}\left(\mathrm{~N}-\mathrm{TiO}_{2}\right)$. B. STEM image and elemental mapping of $\mathrm{N}-\mathrm{TiO}_{2}$. C. UV-vis spectrum of $\mathrm{TiO}_{2}$ and $\mathrm{N}^{-\mathrm{TiO}_{2}}$. 
importantly, the $\mathrm{N}-\mathrm{TiO}_{2}$ can efficiently rejuvenate the mask by facial light irradiation to kill the infected bacteria and virus, which make the mask reusable.

\section{Fabrication of masks}

To fabricate the mask with superior antibacterial and rejuvenation properties, commercial P25 $\mathrm{TiO}_{2}$ were doped using urea as the nitrogen source, and then the doped $\mathrm{N}-\mathrm{TiO}_{2}$ was deposited onto the masks to enable their photocatalytic capacity. After the doping, the color of the $\mathrm{TiO}_{2}$ was changed from white to yellow (Figure 2A). The elementary mapping under a scanning transmission electron microscope (S-TEM) confirmed the existence of the doped nitrogen in the $\mathrm{N}-\mathrm{TiO}_{2}$. As shown in the Figure $2 \mathrm{~B}$, the element of nitrogen along with the elements of both titanium and oxygen have been determined. The atomic fraction of the nitrogen elements in the $\mathrm{N}$ $\mathrm{TiO}_{2}$ was semi-quantitatively analyzed by calculating the peak area of the energy dispersive X-ray spectroscopy (EDX). As shown in the Figure S2, the ratio of titanium (26.6\%) and oxygen (61.2\%) was measured close to 1:2, validated the EDX characterization. In the meanwhile, the atom fraction of the nitrogen was measured at $12.2 \%$, demonstrating the successful doping of nitrogen in the $\mathrm{N}$ $\mathrm{TiO}_{2}$. The nitrogen doping has changed the bandgap of the $\mathrm{TiO}_{2}$. As shown in Figure $2 \mathrm{C}, \mathrm{TiO}_{2}$ without nitrogen doping displayed strong absorbance in the UV and near visible light region (320 $\mathrm{nm}-405 \mathrm{~nm}$ ). After the nitrogen doping, the absorbance edge was shifted to $448 \mathrm{~nm}$, and consequently the $\mathrm{N}-\mathrm{TiO}_{2}$ can significantly absorb visible lights. The bandgap energy can be calculated using the Planck's law:

$$
E=\mathrm{h} \times \check{\mathrm{H}}=\mathrm{h} c / 3=1241 / 3
$$

Where $E$ is the bandgap energy $(\mathrm{eV}), \mathrm{h}$ is the Planck constant, $v$ is the frequency of the light, $c$ is the speed of the light $\left(\mathrm{ms}^{-1}\right)$, 3 i was calculated at $3.06 \mathrm{eV}$, which was decreased to $2.77 \mathrm{eV}$ for $\mathrm{N}_{-} \mathrm{TiO}_{2}$. The mimicking light (2002500nm, 50W) we used was with 5.2\% UV light, 37.2\% visible light and $57.6 \%$ infrared light (Table S1); therefore, these results highlighted the photocatalytic activity of the $\mathrm{N}^{-} \mathrm{TiO}_{2}$ under light irradiation by enhancing the visible light excitation.

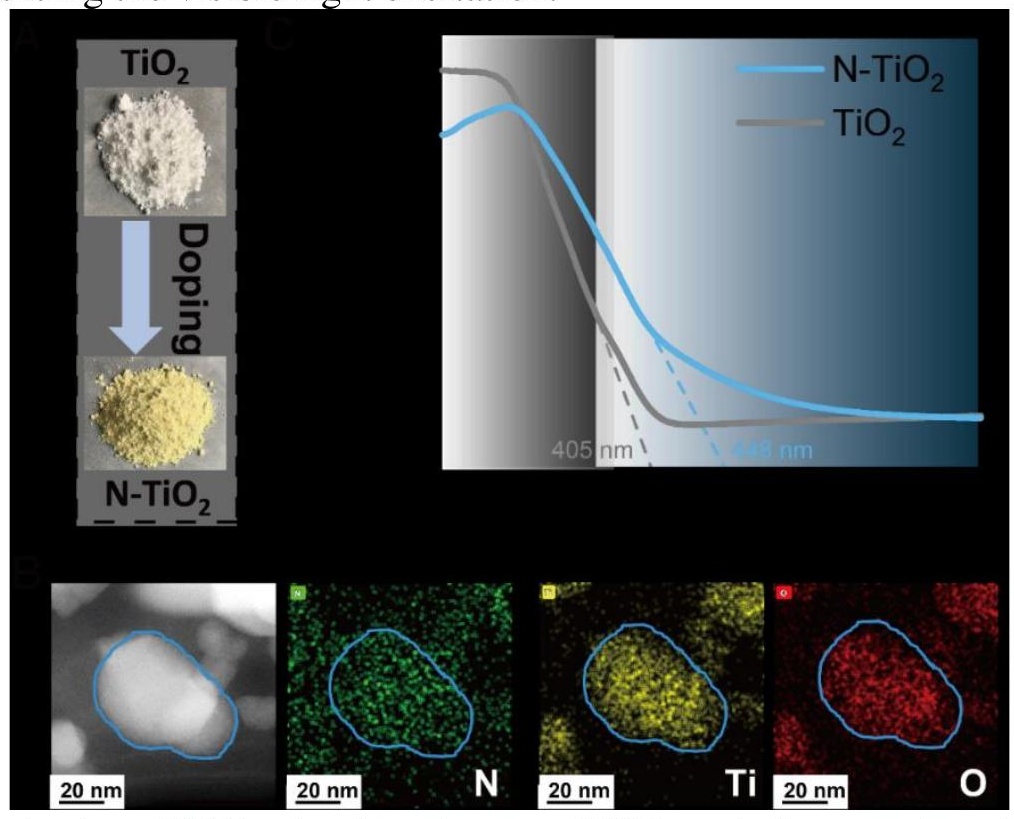

Figure 2. Nitrogen doping of $\mathrm{TiO}_{2}$. A. photo image of $\mathrm{TiO}_{2}$ and nitrogen-doped $\mathrm{TiO}_{2}\left(\mathrm{~N}-\mathrm{TiO}_{2}\right)$. B. STEM image and elemental mapping of $\mathrm{N}-\mathrm{TiO}_{2}$. C. UV-vis spectrum of $\mathrm{TiO}_{2}$ and $\mathrm{N}^{-\mathrm{TiO}_{2}}$. 